2018-03-06

\title{
Investigating Secondary Students Beliefs About Mathematical Problem-Solving
}

Mark Prendergast

Trinity College Dublin, Ireland

Cormac Breen

Technological University Dublin, cormac.breen@tudublin.ie

Aibhin Bray

Trinity College Dublin, Ireland

See next page for additional authors

Follow this and additional works at: https://arrow.tudublin.ie/scschmatart

Part of the Mathematics Commons, Science and Mathematics Education Commons, and the Secondary Education Commons

\section{Recommended Citation}

Prendergast, M. et al. (2018) Investigating secondary students beliefs about mathematical problemsolving, International Journal of Mathematical Education in Science and Technology, DOI: 10.1080/ 0020739X.2018.1440325

This Article is brought to you for free and open access by the School of Mathematics at ARROW@TU Dublin. It has been accepted for inclusion in Articles by an authorized administrator of ARROW@TU Dublin. For more information, please contact arrow.admin@tudublin.ie, aisling.coyne@tudublin.ie,gerard.connolly@tudublin.ie.

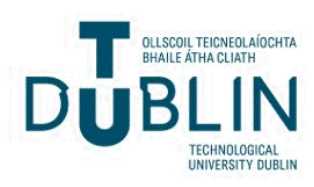




\section{Authors}

Mark Prendergast, Cormac Breen, Aibhin Bray, Fiona Faulkner, Brian Carroll, and Dominic Quinn

This article is available at ARROW@TU Dublin: https://arrow.tudublin.ie/scschmatart/240 


\title{
Investigating Secondary Students Beliefs about Mathematical Problem Solving
}

\begin{abstract}
Many studies over the past thirty years have highlighted the important role of students' beliefs for successful problem solving in mathematics. Given the recent emphasis afforded to problem solving on the reformed Irish secondary school mathematics curriculum, the main aim of this study was to identify Irish students' $(n=975)$ beliefs about the field. A quantitative measure of these beliefs was attained through the use of the Indiana Mathematical Belief Scale, an existing thirty item (five scale) self-report questionnaire. A statistical analysis of the data revealed that students who were further through their secondary education had a stronger belief that not all problems could be solved by applying routine procedures. In contrast, the same students held less positive beliefs than their younger counterparts that they could solve time-consuming problems and that conceptual understanding was important. The analysis also indicated that gender had a significant impact on three of the five belief scales.
\end{abstract}

Keywords: mathematics; beliefs; problem solving; secondary school

\section{Introduction}

In the modern era, societies are required to produce well-educated people who have the ability to adapt themselves to the rapidly changing and developing world [1]. There is an increasing demand from employers and universities for school leavers to be able to apply their knowledge, particularly in mathematics, in varied and unfamiliar contexts [2]. As a consequence, many countries such as Turkey, England, Scotland and Singapore have been implementing comprehensive reform and are prioritising the development of problem solving in their national mathematics curricula [1, 3, 4]. Ireland is no different, and in 2010 a major reform of the entire secondary school mathematics curriculum was rolled out on a phased basis. While the previous curriculum stressed mathematical structures, abstraction and rigorous presentation [5], the current curriculum places a much greater emphasis on problem solving, with 
increased use of contexts and applications that enable students to relate mathematics to their everyday experiences [6]. This shift in the mathematics education paradigm has led researchers to focus more on problem solving and highlight a variety of different factors which may affect students' success in the domain. One such factor is the beliefs that students hold towards problem solving.

McLeod and McLeod [7,p.120] propose that "there is no single definition of the term 'belief' that is correct and true, but several types of definitions that are illuminative in different situations". For the purpose of this study, the authors have concurred with Kloosterman, Raymond and Emenaker's [8] research in which they define beliefs as the personal assumptions from which students make decisions about the actions they will undertake. This implies that certain beliefs lead to particular actions. For example, if a student believes that studying for an examination will be beneficial, then they are more likely to put in the effort. Kloosterman, Raymond and Emenaker [8] noted that the underlying motivation for an action stems from the belief itself.

As far back as 1983, Schoenfeld [9] noted the existence and influence of a system of beliefs that drives students' behaviour when trying to solve mathematical problems. Through the findings of his study, Schoenfeld [9] revealed that students negative beliefs towards mathematics can render certain stored knowledge inaccessible, thereby affecting their ability to use this knowledge to solve problems. This work was expanded upon by Schoenfeld $[10,11]$ as he continued to investigate how an individual's conceptions of mathematics can shape the way in which they engage in activities. It is now generally accepted that the processes involved in mathematical problem solving are affected by factors beyond simply the knowledge that a person holds [12]. Mason and Scrivani [13] determined that students' beliefs about what is useful in learning mathematics affects the cognitive resources available to them. Orton 
[14,p.35] also noted the cognitive processes involved and contended that "successful solutions of problems are dependent on the learner not only having the knowledge and skills required, but also being able to tap into relevant networks and structure in the mind". Thus, given the importance of students' beliefs for successful problem solving and the recent emphasis that it is afforded in the reformed Irish secondary school mathematics curriculum, this study aims to identify Irish students' beliefs about mathematical problem solving.

\section{Students' Beliefs about Problem Solving in Mathematics}

As established in the Introduction, an individual's personal beliefs affects how they approach and react to mathematics and thus guides their progress in problem solving situations [15]. There have been many studies that have investigated the various beliefs students hold towards mathematical problem solving. In the U.S. Schoenfeld [10] found that although students were proficient in applying certain procedures, they frequently developed beliefs that acted as constraints to the construction of mathematical knowledge. This led them to expect that typical mathematical problems should be solved within a matter of minutes. More specifically, they believed that if a problem could not be solved in less than twelve minutes, it was impossible and did not belong in school mathematics. In a subsequent study, Schoenfeld [11] also revealed that students tended to separate the mathematics experienced in the classroom, from abstract mathematics involving creativity and discovery. This resulted in a belief held by many students that all word problems presented in the classroom could be solved (even absurd problems such as "There are 125 sheep and five dogs in a flock. How old is the shepherd?") [16]. Such a view portrays a lack of reflection on the part of the student of what is being asked. 
In another U.S study, Garofalo [17] noted a number of beliefs held by a cohort of secondary school students that were affecting their mathematical performance. For example, the difficulty of a maths problem is due to the size and quantity of the numbers; all problems can be solved by performing one or in rare cases two arithmetical operations; the operation to be performed is determined by the keywords of the problem which are usually introduced in the last sentence; and the decision to check what has been done depends on how much time is available.

Other studies have highlighted even more alternative student beliefs towards problem solving. For example, Lucangeli, Coi, and Bosco [18] found that some fifth grade mathematics problem solvers believed that the size of numbers determined the difficulty of the problem. More recently, Callejo and Vila [19] noted that many secondary school students held the belief that there are always numbers in formulations of mathematics problems.

There have also been many studies investigating the effect that students' beliefs towards problem solving can have on their mathematical outcomes. For instance, Kloosterman and Stage [20] applied a system of beliefs they developed to students in the U.S. and reached the conclusion that beliefs regarding problem solving can affect achievement in the domain. Likewise, Ishida [21] evaluated Japanese students' problem solving skills in a four and a half year longitudinal study, concluding that problem solving beliefs have an effect on the ability to solve problems correctly. In a follow up to the work of Kloosterman and Stage, Mason [12] concluded that Italian high school students' beliefs towards problem solving were a significant predictor of results in mathematics examinations. In 2005, Schommer-Aikins, Duell, and Hutter [22] examined the effects of U.S. students' mathematical beliefs on their mathematical problem solving performance. They found that students' beliefs in the usefulness of the 
subject had a moderate relationship to their problem solving performance. Furthermore, Callejo and Vila [19] and Suthar et al. [23] also found a positive relationship between students' beliefs and their approaches to mathematical problem solving. More recently in a study involving pre-service teachers in the U.K., Stylianides and Stylianides [24] determined that individuals' beliefs interfere with their ability to engage productively with problem solving and can cause low success rates and negative reactions to mathematics more broadly.

Such research makes it clear that there is a link between students' beliefs about problem solving in mathematics and their performance in the subject. An investigation into Irish students beliefs towards problem solving in mathematics, at a time in which the secondary education system is placing a greater emphasis on it, may be of benefit to mathematics educationalists and policy makers in general. This research also provides an opportunity to examine the relationships between students' beliefs about problem solving and their grade level, in particular, their proximity to high-stakes examinations, allowing conjectures to be made about how the subject is taught and learned.

\section{Methodology}

The goal of this study is to investigate Irish secondary school students' beliefs about problem solving in mathematics. Although a number of studies have clearly highlighted the role of students' beliefs about the discipline of mathematics, and more specifically problem solving, no validated instrument to measure these beliefs was available until Kloosterman and Stage [20] constructed and validated the Indiana Mathematical Belief (IMB) scales. This is a Likert-type self-report questionnaire developed and validated to be used with secondary school and college level students. Given the absence of instruments in Ireland for measuring mathematical beliefs at any age level, the authors decided to explore the use of the IMB scales with Irish students. 


\section{The Instrument}

The IMB scales investigate five commonly held beliefs towards mathematical problem solving. These include:

(1) I can solve time-consuming problems: This is the first belief in the IMB scales, and its measurement is used to record students' assumptions about timeconsuming problems. Traditionally, mathematics questions could be solved in a short space of time, leading to students' commonly held belief that all problems should be solvable in a matter of minutes [11].

(2) There are word problems that cannot be solved using simple, step-by-step procedures: Students frequently believe that there are set rules and procedures to follow in mathematics. However, in order to become successful problem solvers, they cannot depend solely on their knowledge of routine mathematical procedures [12]. Good problem solvers have the capacity to solve more complex word problems through the adaptation of these rules and procedures to unfamiliar contexts. Where a student scores on this scale can reflect their level of belief about the existence of a strict set of mathematical rules, as well as how important it is to follow them [20].

(3) Understanding concepts is important in mathematics: Measurement of this construct indicates whether or not it is important for students to understand why an answer is correct, or how the solution was created. Low scores on this belief scale have been associated with low motivation to solve problems in mathematics [20].

(4) Word problems are important in mathematics: This belief relates to how a student views the importance of their computational skill and the selection and application of arithmetic operations to calculate solutions, and compares it to 
their views on the importance of worded problems [20].

(5) Effort can increase mathematical ability: Like the other constructs, students' beliefs about the impact of effort on ability are linked to the motivation that they have towards problem solving in mathematics. Students who try to solve a problem are more likely to succeed than those who are unwilling to put in any effort. This belief can provide insight into how a student may approach a difficult problem solving question and how they cope with different levels of difficulty within mathematical problem solving questions [20].

The overall instrument is made up of thirty statements to which respondents give their opinion on problem solving using a five point Likert-type scale. Eighteen of the questions are worded in the direction of favourable beliefs, with the remainder worded in the opposite direction. Respondents were asked to indicate their level of agreement or disagreement with each item; 1 = strongly disagree, 2 = disagree, $3=$ undecided, $4=$ agree, $5=$ strongly agree. Scoring on negatively worded items was reversed (i.e. $1=$ strongly agree, 2 = agree, $3=$ undecided, $4=$ disagree, $5=$ strongly disagree). Each of the five scales (six statements apiece) are scored separately and there is no overall score. Thus, a high score on each of the scales would indicate more positive beliefs towards mathematical problem solving.

\section{Procedure and Participants}

The IMB scales were distributed to nine different secondary schools in Ireland (Dublin and east midlands area) from December 2016 to April 2017. The schools involved were selected using a convenience sampling method and included four co-educational, three single-sex female and two single-sex male schools.

In Ireland, secondary education comprises of two main cycles, the Junior Cycle (lower secondary level) and the Senior Cycle (upper secondary level), each terminating 
in a high-stakes examination, with a non-compulsory 4th year known as Transition Year

(Table 1). Transition year is a one-year school programme in which the focus is on personal, social, vocational and educational development, providing opportunities for students to experience diverse educational inputs in a year that is free from formal examinations [25].

Table 1: The Organisation of Ireland's Secondary Education System

\begin{tabular}{llll}
\hline Cycle & Year & Typical Age & State Exam \\
\hline \multirow{2}{*}{ Junior Cycle } & $1^{\text {st }}$ & $12-13$ & \\
\cline { 2 - 3 } & $2^{\text {nd }}$ & $13-14$ & Junior Certificate \\
\cline { 2 - 3 } & $3^{\text {rd }}$ & $14-15$ & \\
\hline Transition Year & $4^{\text {th }}$ & $15-16$ & Leaving Certificate \\
\hline Senior Cycle & $5^{\text {th }}$ & $16-17$ & \\
\cline { 2 - 3 } & $6^{\text {th }}$ & $17-18$ & \\
\hline
\end{tabular}

All schools were asked to distribute the scale across a variety of year groupings. The instrument was administered by the class teacher to willing students during normal mathematics class time and completed in 20-25 minutes. In order to address any ethical issues and concerns in relation to answering the questionnaire honestly, information and consent sheets were distributed to all volunteer participants and their parents, informing them that the results of the test would be used for research purposes only and would not have any bearing on their grades.

In total, 975 completed questionnaires were returned. The respondents' ages ranged from 12 to 19 , with the majority (94\%) being between 13 and 18 years. There was a wide range of male (48\%) and female $(52 \%)$ respondents across the different year groups (Figure 1). 


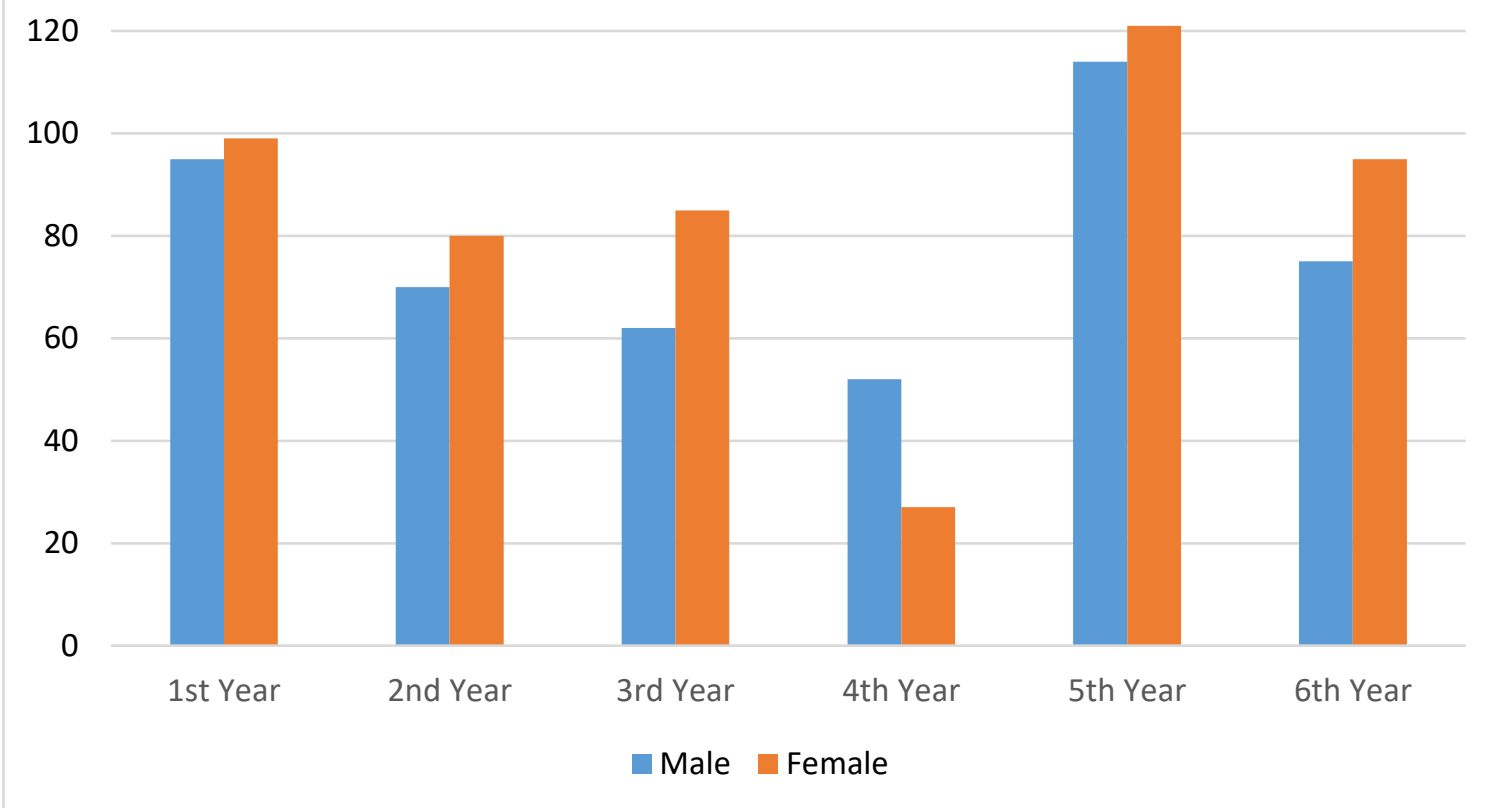

Figure 1. Breakdown of Gender Respondents across the Different Year Groups

\section{Analysis}

The analysis of the data focused on identifying statistically significant differences between year group and gender across the five beliefs associated with the IMB scales. The statistical analysis was conducted using SPSS (Statistical Package for the Social Sciences), which was used to calculate descriptive statistics as well as to perform oneway ANOVA (Analysis of Variance), independent samples $t$-tests, and a Mann-Whitney U test. One-way ANOVA is a statistical procedure used to test the differences between two or more means. This allowed the researchers to investigate, compare and contrast the beliefs of the students in the six different year groups. $T$-tests were used to investigate how much of the variation in beliefs could be explained by the independent variables associated with gender. The independent samples $t$-test is a parametric test that compares the means of two independent groups (male and female) in order to determine whether there is evidence that the associated means are statistically significantly different. However, $t$-tests are only valid when the data is approximately normally 
distributed. This was not the case for all the dependent variables, and so a MannWhitney U test was used in this instance. All of this analysis was conducted to enable the authors to address the following research question:

- What are the beliefs of Irish secondary school students about mathematical problem solving?

\section{Findings}

As this was the first time that Kloosterman and Stage's [20] IMB scales were used with a group of Irish secondary school students, reliability analyses for the five scales of the instrument were conducted. Cronbach's alphas as well as means and standard deviations are reported in Table 2.

Table 2: Means, standard deviations and reliabilities (Cronbach's alpha) $(\mathrm{n}=975)$

\begin{tabular}{lccc}
\hline Scale & Mean & SD & Cronbach's alpha \\
\hline 1. Difficult problems & 20.03 & 4.48 & 0.78 \\
2. Steps & 16.30 & 3.28 & 0.57 \\
3. Understanding & 22.71 & 4.20 & 0.77 \\
4. Word Problems & 17.38 & 3.35 & 0.44 \\
5. Effort & 24.04 & 4.16 & 0.89 \\
\hline
\end{tabular}

After examining the reliability coefficients of the five IMB scales, it can be said that scale 4 ("Word problems are important in mathematics") was not reliable whilst the others can be considered moderately to highly reliable. Overall, with the exception of scale 4, reliability indices are similar to those reported by Kloosterman and Stage [20], based on the final sample involved in the instrument validation procedure. Thus, caution must be applied when interpreting students' scores in scale 4 (Word Problems). 


\section{Analysis of variance across year groups}

In order to provide a clearer picture of the variance across year groups $\left(1^{\text {st }}-6^{\text {th }}\right)$, use was made of one-way, between subjects ANOVAs on each of the five beliefs of the IMB scales, with Bonferroni tests identifying where any significant differences lay.

Table 3 presents the mean ratings of each of the five scales of the IMB instrument, as well as the ANOVA $F$ and $p$-values.

Table 3: Mean ratings for the different years, and the ANOVA F and $p$ values

\begin{tabular}{l|c|c|c|c|c|c|c|c}
\hline & $\mathbf{1}^{\text {st }} \mathbf{Y r}$ & $\mathbf{2}^{\text {nd }} \mathbf{Y r}$ & $\mathbf{3}^{\text {rd }} \mathbf{Y r}$ & $\mathbf{4}^{\text {th }} \mathbf{Y r}$ & $\mathbf{5}^{\text {th }} \mathbf{Y r}$ & $\mathbf{6}^{\text {th }} \mathbf{Y r}$ & $\boldsymbol{F}$ & $\boldsymbol{p}$-Value \\
\hline Difficult Problems & 21.58 & 20.66 & 19.91 & 19.98 & 18.86 & 19.46 & 9.37 & $<0.001$ \\
\hline Steps & 14.77 & 15.85 & 16.80 & 16.44 & 16.67 & 17.42 & 15.3 & $<0.001$ \\
\hline Understanding & 23.69 & 23.93 & 22.45 & 21.96 & 21.98 & 22.08 & 7.70 & $<0.001$ \\
\hline Word Problems & 17.56 & 17.25 & 17.26 & 17.51 & 17.35 & 17.41 & 0.22 & 0.96 \\
\hline Effort & 24.79 & 25.35 & 23.72 & 23.39 & 23.29 & 23.67 & 6.79 & $<0.001$ \\
\hline
\end{tabular}

The range of possible scores for each of the IMB scales goes from a minimum of 6 to a maximum of 30. It is clear from Table 3 that the mean ratings for the Steps and Word Problems constructs are low in comparison to the other beliefs, with beliefs relating to the importance of Understanding and Effort ranking highly across the years. A summary of the significant differences between the year group scores, identified by the one-way ANOVAs and Bonferroni tests is provided in Table 4, with a more detailed description of the results in the following section.

Table 4: Significant differences between year groups
Difficult
Steps
Understanding
Word
Effort

Problems

Problems 


\begin{tabular}{|c|c|c|c|c|c|}
\hline $1^{\text {st }}$ Yr. & $\begin{array}{l}\text { Positive diff } \\
\text { with } 3^{\text {rd }}, 5^{\text {th }} \\
\text { and } 6^{\text {th }} \text {. }\end{array}$ & $\begin{array}{l}\text { Negative diff } \\
\text { with all } \\
\text { years. }\end{array}$ & $\begin{array}{l}\text { Positive diff } \\
\text { with } 4^{\text {th }}, 5^{\text {th }} \text { and } \\
6^{\text {th }} .\end{array}$ & $\begin{array}{l}\text { No } \\
\text { significant } \\
\text { differences }\end{array}$ & $\begin{array}{l}\text { Positive } \\
\text { diff with } \\
5^{\text {th }}\end{array}$ \\
\hline $2^{\text {nd }} \mathrm{Yr}$ & $\begin{array}{l}\text { Positive diff } \\
\text { with } 5^{\text {th }} \text {. }\end{array}$ & $\begin{array}{l}\text { Positive diff } \\
\text { with } 1^{\text {st }} \text {, and } \\
\text { negative with } \\
6^{\text {th }} .\end{array}$ & $\begin{array}{l}\text { Positive diff } \\
\text { with } 3^{\text {rd }}, 4^{\text {th }}, 5^{\text {th }} \\
\text { and } 6^{\text {th }} .\end{array}$ & $\begin{array}{l}\text { No } \\
\text { significant } \\
\text { differences }\end{array}$ & $\begin{array}{l}\text { Positive } \\
\text { diff with } \\
3^{\text {rd }}, 4^{\text {th }}, 5^{\text {th }} \\
\text { and } 6^{\text {th }} \text {. }\end{array}$ \\
\hline $3^{\text {rd }}$ Yr. & $\begin{array}{l}\text { Negative } \\
\text { diff with } 1^{\text {st }} \text {. }\end{array}$ & $\begin{array}{l}\text { Positive diff } \\
\text { with } 1^{\text {st }} \text {. }\end{array}$ & $\begin{array}{l}\text { Negative diff } \\
\text { with } 2^{\text {nd }} \text {. }\end{array}$ & $\begin{array}{l}\text { No } \\
\text { significant } \\
\text { differences }\end{array}$ & $\begin{array}{l}\text { Negative } \\
\text { diff with } \\
2^{\text {nd }} \text {. }\end{array}$ \\
\hline $4^{\text {th }}$ Yr. & $\begin{array}{l}\text { No } \\
\text { significant } \\
\text { differences. }\end{array}$ & $\begin{array}{l}\text { Positive diff } \\
\text { with } 1^{\text {st }} \text {. }\end{array}$ & $\begin{array}{l}\text { Negative diff } \\
\text { with } 1^{\text {st }} \text { and } 2^{\text {nd }} \text {. }\end{array}$ & $\begin{array}{l}\text { No } \\
\text { significant } \\
\text { differences }\end{array}$ & $\begin{array}{l}\text { Negative } \\
\text { diff with } \\
2^{\text {nd }}\end{array}$ \\
\hline $5^{\text {th }}$ Yr. & $\begin{array}{l}\text { Negative diff } \\
\text { with } 1^{\text {st }} \text { and } \\
2^{\text {nd }} \text {. }\end{array}$ & $\begin{array}{l}\text { Positive diff } \\
\text { with } 1^{\text {st }} \text {. }\end{array}$ & $\begin{array}{l}\text { Negative diff } \\
\text { with } 1^{\text {st }} \text { and } 2^{\text {nd }}\end{array}$ & $\begin{array}{l}\text { No } \\
\text { significant } \\
\text { differences }\end{array}$ & $\begin{array}{l}\text { Negative } \\
\text { diff with } 1^{\text {st }} \\
\text { and } 2^{\text {nd }} \text {. }\end{array}$ \\
\hline $6^{\text {th }}$ Yr. & $\begin{array}{l}\text { Negative } \\
\text { diff with } 1^{\text {st }} \text {. }\end{array}$ & $\begin{array}{l}\text { Positive diff } \\
\text { with } 1^{\text {st }} \text { and } \\
2^{\text {nd }} \text {. }\end{array}$ & $\begin{array}{l}\text { Negative diff } \\
\text { with } 1^{\text {st }} \text { and } 2^{\text {nd }}\end{array}$ & $\begin{array}{l}\text { No } \\
\text { significant } \\
\text { differences }\end{array}$ & $\begin{array}{l}\text { Negative } \\
\text { diff with } \\
2^{\text {nd }} \text {. }\end{array}$ \\
\hline
\end{tabular}

\section{Belief 1: Difficult Problems}

A statistically significant difference was recorded between groups according to one-way ANOVA $(F(5,970)=9.365, p<.0001)$. Bonferroni post hoc tests revealed that students' beliefs relating to their ability to solve difficult and time-consuming problems was statistically significantly lower in $3^{\text {rd }}, 5^{\text {th }}$ and $6^{\text {th }}$ year, than in $1^{\text {st }}$ year. As seen in 
Table 3 , the mean for $1^{\text {st }}$ year students is 21.6 , which is the highest mean and can be interpreted that the $1^{\text {st }}$ year students' beliefs about their ability to solve difficult questions are significantly more positive than those of the $3^{\text {rd }}, 5^{\text {th }}$ and $6^{\text {th }}$ year students. That is, the cohort of students who were particularly focused on state examinations were less positive in this regard, with the Senior Cycle students having the lowest means of $18.9\left(5^{\text {th }}\right.$ year $)$ and $19.5\left(6^{\text {th }}\right.$ year $)$.

\section{Belief 2: Steps}

Statistically significant differences were also identified between the year groups in the construct relating to the belief that there are word problems that cannot be solved using simple, step-by-step procedures, $(F(5,969)=15.251, p<.0001) .1^{\text {st }}$ years reported the lowest mean for this belief, and Bonferroni tests confirmed that their mean was statistically significantly lower than all other years. The mean value of the $6^{\text {th }}$ year students for this belief is the highest, and is statistically significantly higher than that of $1^{\text {st }}$ and $2^{\text {nd }}$ years. This indicates that the $6^{\text {th }}$ year students believed to a stronger degree, when compared to all other year groups, that word problems cannot be solved using simple, step-by-step procedures. This is the only one of the beliefs in which the $1^{\text {st }}$ year means were significantly lower than any other year's, and they also has the lowest overall mean (16.3) across all participants.

\section{Belief 3: Understanding}

The belief that conceptual understanding is important in mathematics has an overall mean of 22.7 across the six year groups, the second highest of all of the IMB beliefs, indicating that all year groups have a strong belief in the importance of conceptual understanding in maths. One-way ANOVAs identified statistically significant differences between the year groups $(F(5,969)=7.704, p=.000)$. Bonferroni tests 
indicated that the $1^{\text {st }}$ and $2^{\text {nd }}$ year mean scores were statistically significantly higher than $4^{\text {th }}, 5^{\text {th }}$ and $6^{\text {th }}$ year, with $2^{\text {nd }}$ year scores also being significantly more positive than $3^{\text {rd }}$ years. No significant difference was identified between $1^{\text {st }}$ and $2^{\text {nd }}$ year mean scores.

\section{Belief 4: Word Problems}

The second lowest overall mean score of 17.4 was recorded in relation to the belief that word problems are important in mathematics. This suggests that the students have a lower regard for the importance of word problems compared to most of the other areas of mathematics that were examined. The one-way ANOVA test did not identify any significant differences between the year groups for this construct $(F(5,969)=$ $0.217, p=.955)$.

\section{Belief 5: Effort}

The belief that effort can increase mathematical ability resulted in the highest overall mean of the IMB scales, with a score of 24.035 . Statistically significant differences were identified between the year groups $(F(5,969)=6.785, p=.000) .2^{\text {nd }}$ year scores for this belief were the highest, and statistically significantly more positive than $3^{\text {rd }}, 4^{\text {th }}$, $5^{\text {th }}$ and $6^{\text {th }}$ year. $1^{\text {st }}$ year scores were also statistically significantly higher than $5^{\text {th }}$ years'.

\section{Independent Samples t-Test relating to Gender}

This section of the analysis makes use of independent samples $t$-tests and the MannWhitney test to investigate how much of the variation in the means of each of the beliefs can be associated with the independent variable of gender. With the exception of Word Problems, the values of the dependent variables of Difficult Problems, Understanding, Steps, and Effort were all within the acceptable range $( \pm 2)$ of skewness and kurtosis to prove normal univariate distribution. Thus, independent samples $t$-tests 
were used to explore the means of these four dependent variables, with a nonparametric Mann-Whitney test providing the data for Word Problems.

The independent samples $t$-test indicated that gender had a significant impact on three of the five beliefs, with male students $(n=468)$ having significantly more positive beliefs in relation to the constructs of Difficult Problems and Effort, and females' $(\mathrm{n}=$ 507) beliefs were significantly higher in relation to Steps. No significant differences were identified in relation to gender and Understanding or Word Problems.

- Difficult Problems: In terms of the belief in their ability to solve timeconsuming problems, the $t$-tests indicated that male students' beliefs $(20.6 \pm 4.3)$ were significantly more positive than female students' beliefs $(19.5 \pm 4.6)$, $t(973)=3.79, p<0.001$

- Steps: In relation to the belief that there are word problems that cannot be solved using simple, step-by-step procedures, male students reported significantly less positive beliefs $(15.683 \pm 3.345)$ than female students $(16.856 \pm 3.122), t(972)=$ $-5.660, p<0.001$.

- Effort: Male students' belief that effort can increase mathematical ability (24.441 \pm 4.200$)$ was significantly higher than female students' beliefs $(23.667$ $\pm 4.078), t(972)=2.919, p=0.004$.

\section{Discussion}

The discussion will focus on addressing the main research question of this study: What are the beliefs of Irish secondary school students about mathematical problem solving? The statistical analysis conducted revealed many noteworthy findings regarding such beliefs and the results of each of the five scales of the IMB will be discussed in detail.

\section{Do students believe they can solve time-consuming problems?}


This first belief in the IMB scales is used to record students' assumptions about timeconsuming problems. In the literature review, Schoenfeld $[10,11]$ evidenced that due to the nature of teaching and assessment that exists within a secondary school classroom, students often develop beliefs that act as constraints to the construction of mathematical knowledge. One such constraining belief is that typical mathematical problems should be solved within a matter of minutes.

The mean score for this scale was 20.03 out of 30 . This was the third highest scoring scale and is very close to the results of Mason [12] where a similar cohort of Italian secondary schools students scored 19.72 out of 30. Perhaps the most noteworthy finding regarding this scale in the authors' study is the differences between year groups. The results showed that students in the examination year of the Junior Cycle ( $3^{\text {rd }}$ Year) and both years of the Senior Cycle $\left(5^{\text {th }}\right.$ and $6^{\text {th }}$ Year $)$ were significantly lower than $1^{\text {st }}$ year students. Although this is not a longitudinal study recording changes in student perceptions, such analysis permits the hypothesis that there may be a correlation between higher levels of examination focus and less positive students' beliefs regarding their ability to solve difficult and time-consuming problems.

This is a concerning hypothesis from an Irish mathematics education perspective as there is much literature to suggest that students who do not believe that they can solve difficult or time-consuming problems are more likely to give up more easily [26]. Stylianides and Stylianides [24] highlighted how students who believe problems should be solved in less than five minutes are more likely to give up trying after unsuccessful attempts. Furthermore, in their study Schommer-Aikins, Duell and Hutter [22] noted that if secondary school students believe in quick learning such as this, they are more likely to display poor mathematical problem solving strategies overall. 
While the focus of the reformed Irish mathematics curriculum on problem solving has many advantages, this approach to teaching and learning the subject takes more time $[27,28]$. There have been calls to introduce double mathematics periods to address this issue [29]. However a recent study by Prendergast and O’Meara [30] found that the modal length of an Irish mathematics class remains forty minutes. This is problematic given that a shortage of time inhibits teachers' willingness to involve students in mathematical problem solving and sense-making, particularly as the state examinations draw nearer and teachers feel increased pressure to cover the curriculum content [31]. These time constraints may also be an influencing factor in why students in examination and Senior Cycle years showed a higher tendency to quit trying if they failed to solve a word problem quickly

Furthermore, this scale relating to the students' belief in their ability to solve time-consuming problems was one of two in which male students had significantly more positive beliefs than their female peers. This is comparable to Giovanni and Sangcap's [32] research in which they examined the mathematical beliefs of Filipino university students. Similarly, they found that male students, more than females, believed they could solve time-consuming mathematics. Such findings may be further explained through an analysis of PISA data which regularly measures students' beliefs. Results from PISA (2012) showed that in Ireland, male students have significantly higher levels of motivation, perseverance, self-efficacy, self-concept and have a greater openness to solving mathematical problems than females [33].

\section{Do students believe that there are word problems that cannot be solved with simple,} step-by-step procedures?

This scale had the lowest overall mean (16.30 out of 30) in the study, and the score was again similar to the results of Mason's [12] study with Italian students (16.85 out of 30). 
Such low scores on this construct are worrying as the use of step-by-procedures by students and the prevalence of rote learning within mathematics have been seen to negatively impact students' ability to cope with the ill-structured problems of everyday life [34]. Roth and McGinn [35] maintained that no carry-over exists between schoolbased word problems and everyday problems due to the idealised solution strategy that students use to solve textbook word problems. This argument was echoed by Ogilvie [36] who felt that students struggle with complex and unstructured problems in everyday life, due to the problem solving strategies taught in schools that encourage finding and applying the correct strategy or procedure. She stated that "many students believe that problem solving is being able to apply set procedures or algorithms to tasks and that their job as students is to master an ever-increasing list of procedures" [36,p.1]. Results from this analysis suggest that this may be the case for Irish students.

Despite this somewhat disconcerting finding, it does appear that the students at the higher end of secondary education are more positive in this regard, with the cohort of $6^{\text {th }}$ year students showing the most positive results. This is the only one of the beliefs in which the $1^{\text {st }}$ year means were significantly lower than any other year, which permits the conjecture that $1^{\text {st }}$ years are more likely to employ step-by-step procedures compared with other secondary students. One possible explanation for the less positive results from the $1^{\text {st }}$ year students is that the curricular changes that were introduced in Irish secondary schools were not mirrored in primary schools. Thus $1^{\text {st }}$ year students may still be adjusting to a new approach to mathematics. These findings echo the thoughts that there needs to be greater coherence between the teaching and learning of the subject at both primary and secondary education in Ireland [37].

While this scale may have had the lowest overall mean, it is also the only construct in which female students had significantly more positive beliefs than their 
male peers. Belenky [38] posited that females usually tend to be 'connected knowers' whereas males have a tendency to be 'separate knowers'. In terms of mathematical problem solving, connected knowing would be deemed more open to solving problems in multiple ways and relating to personal experiences [39] and this may explain why females scored significantly higher on this construct.

\section{Do students believe that understanding concepts is important in Mathematics?}

One frequently acknowledged issue with problem solving is students' lack of understanding of what is being asked, as well as a lack of reflection on the solution. A study by Goldberg and Bush [40] identified that students frequently approach a problem with only a single strategy, continue the strategy without reflection, and finish without re-examining the solution. One of the most well-known examples of this is a U.S study in which $29 \%$ of students answered ' 31 remainder 12 ' when asked how many 36-person buses are needed to transport 1128 people [41].

In this study, the mean score for the Understanding of Concepts IMB scale was 22.71 out of 30 , the second highest scoring scale. Given that one of the main aims of the reformed Irish curriculum is to place greater emphasis on student understanding of mathematical concepts $[42,43]$, this should be regarded as a positive finding.

However, the mean score for this scale is still considerably lower than the 24.82 that was recorded in Mason's [12] study, perhaps indicating that there is still room for improvement in this regard. In addition, the results show that the levels of agreement with this beliefs construct were higher amongst the Junior Cycle students. Further research is needed to explore this finding, but it is possible to make a conjecture that the less positive beliefs reported by the Senior Cycle students may be still linked to the high reliance on rote learning and memorisation that existed with the traditional mathematics Leaving Certificate examinations [44]. While changes have been made to this 
assessment in line with the reformed curriculum, it is possible that negative inferences still exist and students are continuing to focus on achieving a correct answer, rather than understanding how they got there.

\section{Do students believe that word problems are important in mathematics?}

Lester and Lambdin [45] believe that problem solving is one of the primary goals of mathematics learning. Despite such importance, the second lowest overall mean score of 17.4 was recorded in relation to the belief that word problems are important in mathematics. The score was consistent and there were no significant differences between the year groups for this construct. Just like the previous scale, Irish students score here was much lower than the 19.67 mean recorded by the students in Mason's study [12]. However similar to Mason's replication with Italian students, the internal consistency of this scale was poor. One possible explanation for the low reliability may be linked to students' interpretation of what constitutes a 'word problem'. Although a definition of a 'word problem' (based on its interpretation in the documentation of the reformed syllabus) was included in the instructions to the questionnaire, students could still attribute different meanings and thus develop different beliefs. Indeed there has been some debate in the literature about what characterises a word problem. Vershaffel, Greer \& De Corte [46] highlighted the common misconception between genuine word problems and worded descriptions of exercises solved by routine mathematical operations. Practitioners must exercise caution in distinguishing real problems as opposed to those with words merely wrapped around computational exercises. In any case, in their development of the instrument Kloosterman and Stage [20] also reported a low reliability coefficient for this scale and so the formulation of the items used may be in need of further attention. 


\section{Do students believe that effort can increase mathematical ability?}

Overall findings from within this research suggest that Irish secondary school students agreed that effort can increase mathematical ability. This scale had the highest overall mean of all of the IMB scales with a score of 24.035 (higher than Italian students' mean of 22.15 in Mason's [12] study). This is a positive finding given that there has been much debate in mathematics education circles in recent years about the value of effort as opposed to a belief in innate ability [47]. Boaler [48] labelled this view of having an innate mathematical ability as the 'elephant in the room'. In subsequent work, Boaler [47] noted that it is important for students to understand that nobody is born knowing how to solve problems or work out mathematical procedures. Much of this is down to hard work and 'grit' $[47,49]$. Dweck [50] determined that such a mind-set is particularly important in solving difficult problems.

Interestingly, this was the second scale in which male students had significantly more positive beliefs than their female counterparts. This finding may also be linked to the notion of having an innate mathematical ability. Mathematics has long been thought of as a male domain $[51,52]$, with a notion existing that women have less ability than men [53]. Boaler [47] argues that these stereotypes shape female students' sense of belonging in mathematics and their willingness to participate and pursue the subject, which is likely to have a negative impact on effort extended.

\section{Limitations of the study}

While it is evident that this study has resulted in some very interesting findings, it is important to be cognisant of any limitations before attempting to draw conclusions. The first limitation of the study that needs to be addressed relates to the sample. This research was conducted using convenience sampling methods, with participants drawn from schools to which the researchers had access. Although this has resulted in a 
relatively large and diverse sample $(n=975)$, there is the possibility that it may not be fully representative of all students across the country.

Secondly, participants (and their parents) were required to give consent for their data to be used in this research. There is no record of the number of students who may have been unwilling to participate, or any potential reasons for this. Although it is unlikely, and measures were put in place to address the issue, there may have been some instances of students providing what they believed to be "correct" answers, rather than answering honestly. It would be very beneficial to gather qualitative interview data in order to complement the quantitative results and to explore the students' beliefs in more depth.

Finally, and perhaps most significantly, the data presented herein does not represent a longitudinal study. For this reason, although it is possible to make conjectures about the reasons for the differences in means across the year groups, it is not possible to make any claims about changes in students' beliefs as they progress through their schooling. This is something that we aim to address in future research.

\section{Conclusion}

Students' beliefs are a crucial factor when examining the possible effects on problem solving within education, as the beliefs people hold "strongly influence the choices they make, the effort they expend, and how long they persevere in the face of challenge" [54,p.193]. Given such importance, and the recent emphasis afforded to problem solving on the reformed Irish secondary school mathematics curriculum, this study makes an important contribution in identifying Irish students' beliefs in this regard.

From a mathematics education perspective, there have been both positive and negative findings. It can be seen as a positive result that the students in the Senior Cycle appear to be more convinced than their younger counterparts that not all problems can 
be solved by applying routine procedures. In contrast, the less positive belief of the more experienced student cohort in their ability to solve time-consuming problems, along with lower levels of agreement with the belief that conceptual understanding is important in mathematics, is worrying. There were also some differences related to gender with male students having significantly more positive beliefs in relation to solving time-consuming problems and the link between effort and increased ability. While these gender discrepancies are concerning and may be linked to the stereotype that mathematics is a male domain, it is encouraging to see that female students had significantly more positive beliefs regarding the Steps construct.

Although identifying these beliefs makes an important contribution to our understanding of students' beliefs about problem solving in mathematics, it is merely a first step. Further research to gather longitudinal data with this cohort, as well as qualitative measures such as interviews and observations, are needed to further explore some of these findings. In addition, the findings of this study are of little value if nothing is done to help students overcome the less positive beliefs that can inhibit learning. In line with the recommendations of Mason [12], once beliefs have been fully assessed, adequate educational interventions should be planned and implemented in the classroom to gradually change naive representations about the nature of mathematics and mathematical problem solving.

\section{Acknowledgements}

We wish to thank all of the mathematics teachers in the nine schools for their interest and co-operation in helping to collect the data, particularly Melanie Kirwan, Alanna Roche, Siobhan Smyth and Paul Sweeney. We are also grateful to all the students who completed the questionnaires, without whom the research would not have been possible. 


\section{References}

1. Guven B, Cabakcor BO. Factors influencing mathematical problem-solving achievement of seventh grade Turkish students. Learning and Individual Differences. 2013;23:131-137.

2. Jones I, Swan M, Pollitt A. Assessing mathematical problem solving using comparative judgement. International Journal of Science and Mathematics Education. 2015;13(1):151-177.

3. Co-operation OfE, Development. PISA 2009 results: learning trends: changes in student performance since 2000 (vol. v). OECD, Paris, France; 2010.

4. Soh CK. An overview of mathematics education in Singapore. Mathematics curriculum in Pacific Rim Countries-China, Japan, Korea and Singapore. 2008:23-36.

5. Lyons M, Lynch K, Close S, et al. Inside classrooms: The teaching and learning of mathematics in social context. Dublin: Institute of Public Administration. 2003.

6. Prendergast M, O'Donoghue J. 'Students enjoyed and talked about the classes in the corridors': pedagogical framework promoting interest in algebra. International Journal of Mathematical Education in Science and Technology. 2014;45(6):795-812.

7. McLeod DB, McLeod SH. Synthesis-beliefs and mathematics education: Implications for learning, teaching, and research. Mathematics Education Library. 2002;31:115-126.

8. Kloosterman P, Raymond AM, Emenaker C. Students' beliefs about mathematics: A three-year study. The Elementary School Journal. 1996;97(1):39-56.

9. Schoenfeld AH. Beyond the purely cognitive: Belief systems, social cognitions, and metacognitions as driving forces in intellectual performance. Cognitive science. 1983;7(4):329-363.

10. Schoenfeld AH. When good teaching leads to bad results: The disasters of'welltaught'mathematics courses. Educational psychologist. 1988;23(2):145-166.

11. Schoenfeld AH. Explorations of students' mathematical beliefs and behavior. Journal for research in mathematics education. 1989:338-355.

12. Mason L. High school students' beliefs about maths, mathematical problem solving, and their achievement in maths: A cross-sectional study. Educational Psychology. 2003;23(1):73-85.

13. Mason L, Scrivani L. Enhancing students' mathematical beliefs: An intervention study. Learning and instruction. 2004;14(2):153-176.

14. Orton A. Learning mathematics: Issues, theory and classroom practice. Bloomsbury Publishing; 2004.

15. Lerch CM. Control decisions and personal beliefs: Their effect on solving mathematical problems. The Journal of Mathematical Behavior. 2004;23(1):21-36.

16. Reusser K. Problem solving beyond the logic of things: Contextual effects on understanding and solving word problems. Instructional Science. 1988;17(4):309-338. 17. Garofalo J. Beliefs and their influence on mathematical performance. The Mathematics Teacher. 1989;82(7):502-505.

18. Lucangeli D, Coi G, Bosco P. Metacognitive awareness in good and poor math problem solvers. Learning Disabilities Research \& Practice. 1997.

19. Callejo ML, Vila A. Approach to mathematical problem solving and students' belief systems: two case studies. Educational Studies in Mathematics. 2009;72(1):111126.

20. Kloosterman P, Stage FK. Measuring beliefs about mathematical problem solving. School Science and Mathematics. 1992;92(3):109-115. 
21. Ishida J. Students' evaluation of their strategies when they find several solution methods. The Journal of Mathematical Behavior. 2002;21(1):49-56.

22. Schommer-Aikins M, Duell OK, Hutter R. Epistemological beliefs, mathematical problem-solving beliefs, and academic performance of middle school students. The Elementary School Journal. 2005;105(3):289-304.

23. Suthar V, Tarmizi RA, Midi H, et al. Students' beliefs on mathematics and achievement of university students: Logistics regression analysis. Procedia-Social and Behavioral Sciences. 2010;8:525-531.

24. Stylianides AJ, Stylianides GJ. Impacting positively on students' mathematical problem solving beliefs: An instructional intervention of short duration. The Journal of Mathematical Behavior. 2014;33:8-29.

25. Prendergast M, O'Meara N. A Time Profile of Mathematics in a" Gap Year" in Irish Secondary Schools. European Journal of Science and Mathematics Education. 2016;4(3):293-304.

26. Ryan KE, Ryan AM, Arbuthnot K, et al. Students' motivation for standardized math exams. Educational Researcher. 2007;36(1):5-13.

27. Cosgrove J, Perkins R, Shiel G, et al. Teaching and Leaning in Project Maths. Insights from teachers who participated in PISA. 2012.

28. Prendergast M, Treacy P. Curriculum reform in Irish secondary schools-a focus on algebra. Journal of Curriculum Studies. 2017:1-18.

29. Association IMT. Project maths and the Irish maths teachers association. Cork: IMTA. 2012.

30. Prendergast M, O'Meara N. A profile of mathematics instruction time in Irish second level schools. Irish Educational Studies. 2017;36(2):133-150.

31. Lubienski S. Mathematics education and reform in Ireland: An outsider's analysis of Project Maths. Bulletin of the Irish Mathematical Society. 2011;67:27-55.

32. Sangcap PGA. Mathematics-related beliefs of Filipino college students: Factors affecting mathematics and problem solving performance. Procedia-Social and Behavioral Sciences. 2010;8:465-475.

33. Perkins R, Shiel G, Merriman B, et al. Learning for life: The achievements of 15-year-olds in Ireland on mathematics, reading literacy and science in PISA 2012. Educational Research Centre; 2013.

34. Jonassen DH. Instructional design models for well-structured and III-structured problem-solving learning outcomes. Educational Technology Research and Development. 1997;45(1):65-94.

35. Roth W-M, McGinn MK. Graphing: Cognitive ability or practice? Science Education. 1997;81(1):91-106.

36. Ogilvie C. Changes in students' problem-solving strategies in a course that includes context-rich, multifaceted problems. Physical Review Special Topics-Physics Education Research. 2009;5(2):020102.

37. Prendergast M, O'Meara N, O'Hara C, et al. Bridging the primary to secondary school mathematics divide: Teachers' perspectives. Irish Educational Studies. Under Review.

38. Belenky MF, Clinchy BM, Goldberger NR, et al. Women's ways of knowing: The development of self, voice, and mind. Vol. 15. Basic books New York; 1986. 39. Cantley I, Prendergast M, Schlindwein F. Collaborative cognitive-activation strategies as an emancipatory force in promoting girls' interest in and enjoyment of mathematics: A cross-national case study. International Journal of Educational Research. 2017;81:38-51. 
40. Goldberg PD, Bush WS. Using metacognitive skills to improve 3rd graders' math problem solving. Focus on Learning Problems in Mathematics. 2003;25(4):36. 41. Carpenter TP, Lindquist MM, Matthews W, et al. Results of the third NAEP mathematics assessment: Secondary school. The Mathematics Teacher. 1983;76(9):652659.

42. Prendergast M, Faulkner F, Breen C, et al. Mind the gap: an initial analysis of the transition of a second level curriculum reform to higher education. Teaching Mathematics and its Applications: An International Journal of the IMA. 2017:hrw024. 43. Treacy P, Faulkner F, Prendergast M. Analysing the correlation between secondary mathematics curriculum change and trends in beginning undergraduates' performance of basic mathematical skills in Ireland. Irish Educational Studies. 2016;35(4):381-401.

44. Curriculum NCf, Assessment. Review of Mathematics in Post-primary Education: Discussion Paper. NCCA; 2005.

45. Lester F, Lambdin D, editors. Teaching mathematics through problem solving: Benefits and research evidence2004: This paper will appear in the MWM conference volume.

46. Kula F. Verschaffel, L., Greer, B., and De Corte, E.(2000). Making Sense of Word Problems. Netherlands: Swets \& Zeitlinger. İlköğretim Online. 2007;6(2).

47. Boaler J. Mathematical mindsets: Unleashing students' potential through creative math, inspiring messages and innovative teaching. John Wiley \& Sons; 2015. 48. Boaler J. The elephant in the classroom: Teaching students to learn and love maths. London: Souvenir Press; 2009.

49. Duckworth AL, Quinn PD. Development and validation of the Short Grit Scale (GRIT-S). Journal of personality assessment. 2009;91(2):166-174.

50. Dweck CS. Even geniuses work hard. Educational Leadership. 2010;68(1):16-

20.

51. Hanna G, editor Reaching gender equity in mathematics education. The Educational Forum; 2003: Taylor \& Francis.

52. Leder GC. Mathematics and gender: Changing perspectives. 1992.

53. Good C, Rattan A, Dweck CS. Why do women opt out? Sense of belonging and women's representation in mathematics. Journal of personality and social psychology. 2012;102(4):700.

54. Pajares F, Miller MD. Role of self-efficacy and self-concept beliefs in mathematical problem solving: A path analysis. Journal of educational psychology. 1994;86(2):193. 